\title{
Comunicando o espírito: a publicização religiosa na Renovação Carismática Católica
}

César Portantiolo Maia

Doutorando em Sociologia pela Universidade da Beira Interior com co-tutela na Universidade Federal de Sergipe. Mestre em Ciências Sociais pela Unifesp. Faz parte do Laboratório de Estudos do Poder e da Política.

E-mail: cesarpmm@hotmail.com

\section{Maira Bittencourt}

Tem pós-doutorado em Comunicação pela Universidade da Beira Interior. Professora efetiva do departamento de Comunicaşão da Universidade Federal de Sergipe. Coordenadora do grupo de pesquisa e extensão em Linguagens e Práticas Jornalísticas. Autora do livro O Príncipe Digital. E-mail: maira_bittencourt@hotmail.com

Resumo: Este trabalho apresenta uma revisão bibliográfica a respeito da Renovação Carismática Católica com ênfase nos seus meios de publicização. Através da retomada de produções acadêmicas que analisam este movimento religioso, propomos investigar seus processos de fundação e crescimento, observando as principais opções adotadas e a íntima relação desenvolvida com os meios de comunicação social. Por fim, buscamos trazer algumas problematizações que envolvem os fenômenos da religião e da comunicação.

Palavras-chave: Renovação Carismática Católica; Igreja Católica; comunicação; publicização.
Abstract: This work presents a bibliographical review on the Catholic Charismatic Renovation with emphasis in its means of diffusion. Through the research of academic productions, which analyze the religious movement, we propose to investigate its processes of formation and growth, observing as main the options adopted and a type of relationship developed with the social media. Finally, we looked for some problems that involve this phenomenon of religion and communication.

Keywords: Catholic Charismatic Renovation; Catholic church; communication; diffusion. 


\section{INTRODUÇÃO}

A Renovação Carismática Católica (RCC) é um movimento da Igreja Católica que está no Brasil há 52 anos. No entanto, expandiu-se numericamente, de forma vertiginosa, na década de 1990. A partir dos grupos de oração, dos encontros de massa, da presença nos meios de comunicação e dos padres cantores, as lideranças do movimento trouxeram grande número de indivíduos que estavam sem religião, bem como católicos desanimados com suas práticas religiosas e que desejavam ter outras experiências de fé.

Um dos caminhos prioritários escolhidos pela RCC para propagar a fé católica foi a utilização da comunicação de massa. Basicamente se destacam dois processos: os encontros para multidões (como pregações, congressos e shows) e as inserções nas mídias (rádio, televisão e internet).

Ao longo de sua história, o movimento criou e impulsionou verdadeiros sistemas de comunicação, como a Comunidade ${ }^{1}$ Canção Nova, que hoje possui concessões de rádio e televisão, além de site e página no Facebook. Todos estes canais possuem conteúdo exclusivo.

Para situar o leitor a respeito do que estamos analisando, primeiramente apresentamos uma breve retomada histórica da fundação do movimento. Identificamos, de forma sucinta, suas principais práticas e alguns elementos de sua estrutura organizacional. Sem a pretensão de expor toda a trajetória, apenas destacamos os elementos que julgamos essenciais para o entendimento

1.A palavra "comunidade", para além do sentido comum utilizado no Cristianismo, que expressa uma reunião de pessoas que partilham crenças e forma de viver, tem para os carismáticos um sentido bem específico. $\mathrm{Na}$ RCC, expressa um nível de organização interna do movimento, pois as comunidades são um grupo bem específico dedicado ao trabalho de evangelização, valendo-se de metodologia própria e com objetivos pré-determinados (meios de comunicação, dependentes químicos, moradores de rua). Dividem-se em dois tipos: "comunidade de vida" e "comunidade de aliança"; no primeiro, as pessoas vivem juntas num mesmo local; e, no segundo, apenas compartilham o carisma (jeito de viver e de agir) nos diferentes espaços que habitam.

2.Cenáculo é o nome do local onde os discípulos de Jesus estavam reunidos (BÍBLIA, Atos, 2, 1-13). do problema analisado.

Na sequência, tratamos dos meios utilizados pela RCG para tornar-se conhecida, angariar adeptos e transpor os limites estabelecidos para o religioso. Nesse processo, algumas questões teóricas e problematizações vão sendo agregadas, a fim de aprofundar o debate a respeito das funções sociais que cumprem os processos de publicização adotados pela RCC.

\section{ORIGEM E ORGANIZAÇÃO DA RENOVAÇÃO CARISMÁTICA CATÓLICA (RCC)}

A RCC é considerada uma manifestação do pentecostalismo dentro do catolicismo, pois trouxe para a Igreja Católica algumas práticas religiosas que não eram comuns em seu meio. Essas práticas já faziam parte dos grupos pentecostais e evangélicos e foram migrando para o catolicismo. Isso, em seus primeiros anos de atuação, gerou algumas ressalvas por parte da hierarquia eclesial e também de leigos.

O termo "pentecostal" remete a fato narrado na Bíblia, no livro Atos dos Apóstolos, quando os discípulos de Jesus, reunidos no "cenáculo"2", em data próxima da festa judaica de Pentecostes, receberam o "Espírito Santo" em forma de línguas de fogo. Esse fato fez que os discípulos se animassem para convencer outras pessoas a seguir sua crença. Pentecostes, a partir de então, 
ficou conhecido para os cristãos como envio do "Espírito Santo". É o momento de efervescência espiritual dos discípulos de Jesus e de impulsionamento para a missão de propagar o cristianismo.

No contexto eclesial, de surgimento da RCC, o catolicismo vivenciava os efeitos da maior transformação do século XX, ocasionada pelos desdobramentos do Concílio Vaticano II (aggiornamento), que ocorreu na primeira metade da década de 1960. Este concílio acarretou mudanças práticas na Igreja, na tentativa de fazer que ela dialogasse com as mudanças sociais que estavam ocorrendo. Entre as principais alterações propostas, podem-se destacar a reforma litúrgica e a aproximação dos diferentes níveis da hierarquia eclesial, dando a leigos maiores autonomia e protagonismo na vida dos grupos religiosos ${ }^{3}$.

De acordo com Reginaldo Prandi ${ }^{4}$, o surgimento do movimento Carismático Católico se deu em 1967, nos Estados Unidos. Nesse momento, membros da Universidade Duquesne, localizada em Pittsburgh, que já possuíam contato com grupos pentecostais protestantes e estavam insatisfeitos com o seu processo de fé, se reuniram em um retiro para realizar um contato mais íntimo com Deus.

Cinco anos após seu surgimento nos Estados Unidos, a RCC chegou ao Brasil. Trazida pelos padres jesuítas Eduardo Dougherty e Haroldo Rahm, instalou-se em Campinas (SP) e rapidamente se espalhou para todo o Brasil. A partir de então começaram a fundação de grupos de oração e a realização de grandiosos encontros de massa.

Após ter estado no Brasil no ano de 1966, padre Eduardo retornou para a América do Norte, onde realizou estudos teológicos na Universidade de Toronto e teve a experiência do "batismo no Espírito Santo". Em 1969, retornou ao Brasil e começou a atuar junto com padre Haroldo no Centro Kennedy, em Campinas, destacando-se, nos primeiros anos de RCC, pela sua capacidade empreendedora $^{5}$. Ele fundou comunidades e meios de comunicação social, como a Comunidade de Aliança Jesus Te Ama, cuja principal função é formar grupos de partilha de orações, além da Associação do Senhor Jesus e do Centro de Produção Televisiva Século XXI, que trataremos mais para frente.

Nesse sentido é importante destacar a noção apresentada por Edênio Valle ${ }^{6}$, que aquilata o movimento carismático brasileiro ao processo de apropriação cultural vivenciado na América Latina. O autor identifica que determinados modelos de ser e viver produzidos no hemisfério Norte, mais especificamente nos Estados Unidos da América, foram absorvidos pelo sul, ou seja, pelos latino-americanos. A RCC se enquadraria neste contexto como um típico produto norte-americano que foi incorporado pela Igreja Católica brasileira. Uma expressão do pentecostalismo estadunidense trazida para cá.

Por ser algo novo e por não ter chegado através das vias institucionais, ou seja, algo que não foi trazido pelo Vaticano, em seu início a relação do movimento com o clero não foi das mais amistosas, havendo momentos de maiores e de menores atritos. No entanto, deve-se considerar que a Igreja Católica possui muitos grupos e setores que diferem ideologicamente;
3.CARRANZA, Brenda. Renovação Carismática Católica: origens, mudanças e tendências Aparecida: Santuário, 2000. 4.PRANDI, Reginaldo. Um sopro do espírito. São Paulo: Edusp, 1998.

5.CARRANZA, op. cit.

6.VALLE, Edênio. A Renovação Carismática Católica: algumas observações. Estudos Avançados, v. 18, n. 52, p. 97-107, 2004. Disponível em: http://www. scielo.br/pdf/ea/v18n52/ a08v1852.pdf. Acesso em: 6jun. 2019. 
sendo assim, alguns bispos e padres estiveram sempre na oposição, enquanto outros apoiaram incondicionalmente.

\section{PRÁTICAS RELIGIOSAS DA RCC}

A RCG tem como sua célula-base o grupo de oração, com encontros semanais que duram aproximadamente duas horas. De acordo com Brenda Carranza ${ }^{7}$, no grupo de oração os participantes da RCC satisfazem suas necessidades espirituais e desligam-se dos problemas e do mundo material exterior ao grupo. Esse desligamento proporciona ao participante momentos de paz, nos quais deixa de lado suas frustrações e preocupações do dia a dia. "Assim os participantes dos grupos de oração procuram e encontram uma resposta religiosa às suas aflições cotidianas, reelaborando sua maneira de ver e agir na sociedade" ${ }^{8}$.

Desse modo, o encontro do grupo pode ser considerado um momento de resolver problemas, não somente os objetivos (materiais e físicos), mas também os subjetivos, ou ligados a questões existenciais, psíquicas e afetivas, sendo a partir daí que se dá a possibilidade de reelaboração e ressignificação da convivência em sociedade pelo participante.

Muito comum nas práticas da RCC, o "batismo no Espírito Santo", ou "derramamento do espírito", caracteriza-se pela percepção sensível do Espírito Santo já recebido pelo fiel no sacramento ${ }^{9}$ do batismo. A ação do espírito possibilita ao fiel um reordenamento em sua vida, e tal ordem poderá ser reproduzida nos discursos empreendidos no espaço público, o que implica a publicização de argumentos amparados em preceitos religiosos.

De acordo com as orientações do movimento, muitos cristãos católicos, que foram batizados na Igreja, não tiveram a percepção do recebimento do "Espírito Santo". Dessa forma, o batismo no espírito poderia dar ao fiel a oportunidade de vivenciar a ação "transformadora" do Espírito de Deus, sendo essa transformação, nos diversos aspectos de sua vida e também de suas concepções a respeito da sociedade, participação política e preocupação com problemáticas sociais.

Na maioria dos encontros da RCC, é utilizado o "dom de línguas", ou

7.CARRANZA, op. cit.

8.Idem, p. 51.

9.0 termo "sacramento", pode ser entendido como um ato simbólico e com várias ações rituais envolvidas, tendo como função estabelecer uma relação do fiel que o está recebendo com Deus. O sacramento é ainda entendido como a "ação salvífica de Deus" que se dá a partir da orientação de alguém autorizado (um administrador do sagrado), da assembleia presente e da abertura do fiel em receber tal ação divina. glossolalia. Sendo um dos dons do Espírito Santo, expressa uma maneira de orar muito diferente da convencional. É uma oração sem vernáculo específico e que não possibilita uma inteligibilidade racional. Por causarem forte impacto e surpresa ao público externo ao movimento, as práticas da glossolalia e do batismo no Espírito Santo nem sempre ganham publicidade, mas são importantes para a manutenção das práticas simbólicas do movimento.

Dentre os instrumentos de vivência da fé dos carismáticos, destacam-se, também, os encontros de massa, que ocorrem em nível nacional ou regional. Nesses encontros, durante o dia ocorrem pregações de pessoas com destaque na RCC e apresentações de bandas, além de missas, curas e milagres.

Esses eventos apresentam um duplo movimento; de um lado, atraem o católico afastado, mostrando-lhe um catolicismo vigoroso, capaz de aglutinar maiorias 
e mostrando um relativo poder e hegemonia da Igreja Católica. Do outro lado oferece um serviço religioso de massas que favorece o trânsito religioso ${ }^{10}$.

Além das funções relacionadas à fé dos indivíduos, os encontros de massa contribuem para que o movimento ganhe publicidade, ou seja, que se torne mais conhecido nos espaços "não eclesiais". Isso ocorre, principalmente, quando tais eventos se dão em ambientes que não são confessionais, como campos de futebol e ginásios, pois demonstram a capacidade do movimento de ultrapassar as "fronteiras" da Igreja Católica e ocupar outros espaços.

Constitui também um elemento já característico das práticas religiosas do movimento as performances artísticas, principalmente musicais. Abaixo transcrevemos uma música tipicamente cantada na RCC. A partir dela podem-se perceber algumas características do movimento expressas nos versos do autor.

Invocamos (Eros Biondini)

Invocamos o teu nome, invocamos o teu poder, invocamos a tua presença no meio de nós.

Invocamos o teu nome, invocamos o teu poder, invocamos a tua presença, no meio de nós.

Manifesta Senhor o teu poder, manifesta Senhor a tua força, manifesta Senhor neste lugar, o teu grande amor, que tudo pode curar.

Manifesta Senhor o teu poder, com prodígios, milagres, sinais.

Manifesta Senhor neste lugar, o teu grande amor que tudo pode curar.

A música se restringe a essas duas estrofes e pode ser considerada uma música de adoração ${ }^{11}$. Percebe-se nela uma relação direta do crente com Deus, "invocando o Seu nome" e "a Sua presença" entre as pessoas, numa relação que se fará possível através de visões e percepções subjetivas. O participante quer ver ou sentir Deus e as transformações que Ele faz na sua vida, melhorando a situação financeira, curando um mal físico ou qualquer problema pessoal.

No penúltimo verso, percebe-se o pedido para que Deus se manifeste com "prodígios", "milagres" ou "sinais". As manifestações sobrenaturais, comumente chamadas de milagres e que demonstram claramente a intervenção de Deus na vida dos participantes de maneira objetiva, são constituintes do sistema de crenças do carismático.

No entanto, cabe ressaltar que, embora as manifestações de Deus estejam atreladas, na maioria das vezes, a momentos de êxtase religioso, elas são muito valorizadas pelo movimento e tidas como primordiais para as mudanças no modo de vida dos participantes. Assim, a ação do "Espírito Santo" tem que se expressar, também, numa nova vida de quem o recebe, ou seja, os conceitos e concepções de ordem, que fazem parte das orientações dos carismáticos, devem ser incorporados pelos fiéis. Esta transmutação do campo espiritual para

10.CARRANZA, op. cit., p. 53. 11.Na RCC, uma das práticas tradicionais da Igreja Católica que é adotada com nova "roupagem" é a adoração ao santíssimo sacramento. Sempre presente nos encontros de massa, é muito valorizada por seus membros. Tendo como característica a utilização de cantos fortes, que exaltam o nome de Jesus, é geralmente nesses momentos que se dão os milagres, curas e libertações. 
o prático formal possibilita que ideias defendidas pelo movimento permeiem esferas e passem a fazer parte do debate público.

\section{A MÚSICA E OS MEIOS DE COMUNICAÇÃO DE MASSA: PROCESSOS DE MIDIATIZAÇÃO E PROPAGAÇÃO DA FÉ}

A música e os meios de comunicação social, como rádio, TV e internet, são importantes instrumentos do processo de propagação da fé da RCG. De acordo com André Ricardo de Souza ${ }^{12}$, a partir da década de 1980 ocorreram muitos investimentos, realizados por lideranças carismáticas, visando o desenvolvimento de emissoras de rádio e TV. Ocuparam posições de destaque, nesse processo, o padre Eduardo Doughert, fundador da Rede Século XXI, e o padre Jonas Abib, que fundou a comunidade e TV Canção Nova. Foi através dos meios de comunicação que cantores e bandas também conseguiram grande repercussão nacional.

A Rede Século XXI possui canal de televisão, revista de circulação nacional, site e páginas em redes sociais. A Comunidade Canção Nova, além das emissoras de TV e rádio, conta com uma editora, uma gravadora e um site.

Souza $^{13}$ destaca que tanto a Rede Século XXI quanto a Canção Nova ampararam-se para seu crescimento e estruturação num projeto de marketing desenvolvido por profissionais especializados, bem como na formação dos "clubes de sócios", nos quais o público que acompanha a programação pode estar patrocinando a manutenção do meio de comunicação e garantindo, assim, o financiamento de seus custos.

As mídias não são utilizadas somente para os momentos de oração e louvor, mas se transformaram em algo que pode ser assistido, acompanhado, comprado e consumido, seja a partir dos CDs e DVDs gravados, ou de suas programações, que incluem telejornais, entretenimento adulto e infantil e teledramaturgia.

Quando essas outras instituições - no caso, a Igreja e seus membros - se utilizam da mídia para apresentar informações, construir relacionamentos sociais e produzir atenção por meio de sua comunicação, acontece o que Stig Hjarvard ${ }^{14}$ classifica como um processo de midiatização da cultura e da sociedade.

A mídia entra nesse contexto social com a intenção de condicionar e agenciar a reflexão ou ação desse determinado grupo ${ }^{15}$. Sabendo que o que passa pela TV e rádio se torna rapidamente motivo de debate do público, os meios de comunicação absorveram, desde os anos 1980, esse caráter não apenas informativo, mas também de fins comerciais e institucionais. A mídia se afastou de um direcionamento dividido entre dois setores isolados: informação e entretenimento, ou, em outras palavras, jornalismo e ficção, para absorver outros campos do interesse público e de organizações da sociedade. Então, surge esse misto de informação e vivência sociais, testemunhos, música, igreja, entretenimento e jornalismo com aspecto de comunidade de fé. Junto com isso, passa-se cada vez mais a comercializar essas informações religiosas. 
Por ser algo profundamente imbricado entre as instituições religiosas, é chamado midiatização, e não apenas mediação. A mídia faz parte da estrutura de comunicação entre as instâncias em todo o seu planejamento e ação.

A midiatização diz respeito às transformações estruturais de longa duração na relação entre a mídia e outras esferas sociais. Em contraste à mediação, que lida com o uso da mídia para práticas comunicativas específicas em interação situada, a midiatização preocupa-se com os padrões em transformação de interações sociais e relações entre os vários atores sociais, incluindo os indivíduos e as organizações. Desta perspectiva, a midiatização envolve a institucionalização de novos padrões de interações e relações sociais entre os atores, incluindo a institucionalização de novos padrões de comunicação mediada ${ }^{16}$.

Com a midiatização. aparecem novas relações e as plataformas de comunicação passam a ser redesenhadas, "principalmente no âmbito da circulação de mensagens, situando o status dos receptores de mensagens em novas condições, transformando-os, também, em produtores de atividades discursivas midiáticas"17.

Nesse sentido, há inclusive uma confusão do público, que, em alguns momentos, nem enxerga a mídia no processo, mas apenas o produto que chega. Parte do público vê a TV Globo como mídia, porém não entende a Canção Nova como sendo igualmente um espaço de mídia. Ela passa a ser mais um espaço do sagrado.

Klein trata esse fenômeno como uma invasão das mídias visuais no terreno do sagrado. Seria um processo de interseção entre as imagens sagradas e as imagens de mídia, e "a percepção da imagem passa a ser a percepção da coisa em si, uma ilusão semiótica que sempre acompanhou o homem, como se pixels pudessem se converter em átomos"18. Pela televisão, o público passaria a fazer parte daquela realidade. Seria como se não existisse a barreira midiática, ou como se esta se tornasse invisível. Isso é ainda mais latente na comunicação religiosa. "É através das mídias eletrônicas que percebemos novas dimensões temporais e manifestação do sagrado [...] Nunca o casamento entre as igrejas e a TV demonstrou tanta força" ${ }^{\prime 1}$. Isso ganha ainda mais notoriedade porque aquilo que é midiático também transborda para o espaço físico, fazendo parte das celebrações, igrejas e outros espaços físicos da fé.

O relacionamento entre os fiéis e as celebridades midiáticas também fazem parte desse imaginário. Essas figuras auxiliam nessa aproximação entre vida religiosa, fé e mídia. São, em muitos casos, o grande elo que permeia os espaços físicos e midiáticos.

No campo musical, uma das celebridades midiáticas da RCC, que ganhou destaque a partir da década de 1990, foi o padre Marcelo Rossi. Em 1998, com a gravação do álbum Músicas para Louvar ao Senhor, vendeu 3,2 milhões de cópias. Além do significativo número de CDs vendidos, o padre Marcelo se destaca pela capacidade de reunir grandes massas em encontros e missas em que está presente, bem como pela participação em programas de TV com vasta audiência, como "Domingão do Faustão", "Domingo Legal" e algumas exposições em parceria com a apresentadora Xuxa Meneghel ${ }^{20}$.
16.HJARVARD, op. cit. 2014, p. 24

17.FAUTO NETO, Antônio. Epistemologia do zigue-zague. In: FERREIRA, Jairo; FREITAS, Luiz Antonio Signates; PIMENTA, Francisco José Paoliello (org.). Estudos da comunicação: transversalidades epistemológicas. São Leopoldo: Editora Unisinos, 2010. p. 79-100, p. 87.

18.KLEIN, Alberto. Imagens de culto e imagens de mídia: interferências midiáticas no cenário religioso. Porto Alegre: Sulina, 2006, p.139.

19.Idem, pp. 139 e 176. 20.SOUZA, op. cit. 
21.FERNANDES, Sílvia Regina Alves. Padres cantores e a mídia: representações da identidade sacerdotal. Ciências Sociais e Religião Porto Alegre, n. 7, p. 131 155 , set. 2005, p. 132.

22.Idem.

23.FLORES, Ana Cassia. Práticas midiatizadas da Canção Nova na Internet, afetação de lógicas comunicacionais católicas e midiáticas. Dissertação (Mestrado em Comunicação Midiática) - Universidade Federal de Santa Maria Santa Maria, 2010, p. 36.

24.RASLAN FILHO, Gilson Soares. Dai-me almas: o pastoreio midiatizado da TV Canção Nova. Tese (Doutorado em Interfaces Sociais da Comunicação) - Escola de Comunicações e Artes, Universidade de São Paulo São Paulo, 2010.
Padre Marcelo Rossi pôde ser considerado o empreendedor de uma fase, na qual o sacerdócio ganhou destaque e o nome de outros padres juntaram-se ao dele. Apenas para exemplificar, citamos alguns nomes atuais: padre Reginaldo Manzotti, padre Alessandro Campos e padre Fábio de Melo. Isso não significa que antes do padre Marcelo Rossi não tenham existido padres cantores, ou com potencial midiático, porém esses não tiveram a mesma capacidade de mobilização e inserção nos meios de comunicação social.

Destacamos que, apesar da RCC ter se firmado historicamente com um discurso de amor à hierarquia da Igreja e em defesa da vivência dos sacramentos, remetendo à institucionalização da fé, os resultados do trabalho dos padres midiáticos não apontam necessariamente neste sentido. $\mathrm{O}$ fato de os fiéis identificarem-se com esses sacerdotes não garante fidelidade à Igreja Católica, seus dogmas e sacramentos. "A relação dos fiéis com Pe. Rossi se estabelece pautada no reconhecimento de seu carisma em virtude das 'provas' ou dos sinais que ele transmite aos adeptos" ${ }^{21}$. A forte midiatização destas figuras religiosas, embora apropriadas dos "bens simbólicos" da Igreja Católica, não está necessariamente atrelada à instituição, mas ao poder pessoal da liderança religiosa.

Embora não seja possível afirmar a dimensão da prática do convertido através da midiatização, na qual se constrói uma relação muito direta com o portador do carisma, havendo pouca mediação institucional, podemos perceber que, pelo fato de as lideranças serem católicas, gera-se um impacto direto na captação de adeptos para a religião. As pessoas que buscam estes padres, em função da crença que depositam neles enquanto mediadores da ação divina com poderes para curar ou realizar coisas extraordinárias, estão, em última instância, buscando uma liderança da Igreja Católica, o que gera efeito sobre o seu contingente numérico.

De acordo com Sílvia Fernandes ${ }^{22}$, a atuação dos padres cantores, além de potencializar a manutenção quantitativa dos adeptos ao catolicismo, influenciou a formação de um novo estilo de "catolicismo popular". Para além das rezas, das festas e dos santos, este novo estilo de vivência da fé tem na audiência aos padres, nos encontros de massa (pregações e shows) e na aquisição de CDs, livros e outros materiais religiosos seus principais fatores de vivência e reavivamento.

Nessa perspectiva, merecem destaque, também, as considerações de Ana Cassia Flores ao identificar que, se a Igreja Católica conseguiu influenciar os indivíduos através de sua presença na mídia, ela também foi influenciada neste processo. Essencialmente, "a Igreja presente na mídia hoje não é a mesma Igreja que historicamente conhecemos, mas o resultado de processos de afetações e negociações que modificam o que já existia e que fazem emergir uma Igreja midiatizada” ${ }^{23}$. É um processo que transformou e transforma um dos principais elementos da Igreja: a forma como ela se comunica e as práticas religiosas que transmite.

No mesmo sentido, Gilson Soares Raslan Filho ${ }^{24}$ apresenta sua crítica aos processos midiáticos do catolicismo latino-americano. Olhando de forma mais específica para a TV Canção Nova, o autor destaca as influências recíprocas de 
processos em que a religião, historicamente crítica aos meios de comunicação social, se vale deles para empreender o seu "pastoreio", sendo por este meio influenciada. Isso é o que teria acontecido com a Canção Nova, um processo no qual o capitalismo que impregna os meios de comunicação comerciais teria penetrado, também, nesta comunidade religiosa, aproximando-a desse sistema econômico.

É importante destacar que a liderança não substitui o papel desempenhado pela instituição religiosa, que está mais atrelado ao controle e à administração do sagrado, mas se cria uma espécie de atalho, no qual o sentido da fé não passa necessariamente por ritos e sacramentos, ligando-se de forma direta ao líder carismático. Configura-se, assim, um fenômeno religioso tipicamente contemporâneo, explicado de forma pormenorizada pela socióloga francesa Danièle Hervieu-Légeur (2008), no qual determinadas figuras humanas, muito mais do que instituições, passam a dar significado a crenças e vivências religiosas.

Devemos considerar que os padres citados acima não têm necessariamente relação direta com a Renovação Carismática Católica, porém incorporam em suas ações (formas de rezar, de cantar e de fazer as pregações) elementos historicamente característicos desse movimento religioso. Este processo é designado por Sílvia Fernandes ${ }^{25}$ como "contaminação" de um éthos carismático. Embora possamos questionar o sentido negativo que adquire o termo "contaminação", é importante perceber quanto a RCC, ao longo de sua história de pouco mais de meio século, conseguiu transpassar suas fronteiras e influenciar outras realidades da Igreja Católica.

\section{PERMEANDO OUTRAS ESFERAS}

Embora o Brasil tenha sido proclamado como república no ano de 1889, o que, invariavelmente, implicaria a separação entre Estado e Igreja, pode-se dizer que esse processo não passou de uma formalidade ${ }^{26}$. Ao longo da história do Brasil republicano não faltam exemplos que demonstram a permeabilidade entre o religioso e o político, como a presença do ensino religioso em escolas públicas, muitas vezes carregado de conotação confessional, as imagens religiosas em prédios públicos e, mais recentemente, a formação das bancadas religiosas no poder Legislativo.

Aproveitando a oportunidade de galgar influência, deixada pela separação incompleta entre Estado e religião, o processo de publicização vivenciado pela RCC não deixou esquecida a inserção na política partidária. Embora tímida no princípio do movimento, a prática foi alterada com o passar dos anos, e, de acordo com Carlos Eduardo Pinto Procópio ${ }^{27}$, existe atualmente uma ação intencional do movimento na tentativa de eleger candidatos que representem os seus interesses nos poderes Legislativo e Executivo.

Silveira $^{28}$ identifica que a partir de 2003 foi organizado um projeto de inserção da RCG na política. A intenção seria utilizar o poder de mobilização
25FERNANDES, op. cit.

26 Se tomamos como referência a experiência de outros países, principalmente europeus, percebemos que o padrão nas repúblicas "proclamadas" foram a laicidade do Estado e a respectiva autonomização do regime republicano em relação às instituições religiosas.

27PROCÓPIO, Carlos Eduardo Pinto. Carismatismo católico e eleições no Brasil. Ciências Sociais e Religião, v. 14, n. 16, p. 7999, jun. 2012.

28SILVEIRA, Emerson José Sena da. Terços, "santinhos" e versículos: a relação entre católicos carismáticos e a política. Revista de Estudos da Religião-REVER, ano 8, p. 54-74, mar. 2008. 
das lideranças leigas e os meios de comunicação ligados ao movimento para potencializar candidaturas alinhadas a seus interesses. A expectativa era de inserção de seus membros na política com o argumento da necessidade de transformação moral a partir dos valores cristãos, mas sem criar ou vincular o movimento a uma legenda partidária específica.

É importante destacar que, embora se identifique uma ação orientada do movimento no sentido de patrocinar candidaturas alinhadas a seus interesses, isso não ocorre ao nível de muitas igrejas pentecostais, pois estas, em alguns casos, têm pastores orientando publicamente o voto dos fiéis. O apoio público do clero carismático a determinado político é algo raro de ser observado, e, quando ocorre, é sempre recheado de críticas por parte da hierarquia ou dos outros setores da Igreja.

Analisando a presença dos carismáticos na política brasileira, Marcos Vinicius de Freitas Reis ${ }^{29}$ destaca a significativa presença de candidatos ligados à RCG no Partido Humanista Cristão (PHS), bem como as reivindicações desses políticos vinculadas a preceitos religiosos de defesa da vida, oposição ao aborto, ao casamento homoafetivo e à eutanásia.

Um exemplo prático que elucida a articulação entre a liderança religiosa midiatizada e seu potencial de influência e inserção na política é o caso do deputado federal Eros Biondini (Pros). Membro da RCC há mais de 25 anos, faz shows e pregações incorporando o papel de uma liderança do movimento, e, hoje, na sua atividade parlamentar atua junto da bancada religiosa e defende interesses e valores morais importantes para o movimento.

Outro exemplo deste processo é o do missionário Flavinho (PSB), que, após ter atuado durante 27 anos junto à Comunidade Canção Nova, foi eleito deputado federal no pleito de 2014. Em entrevista ao G1, concedida no início do mandato, o deputado destacou que não pretendia atuar no Congresso como religioso, mas que teria como suas principais bandeiras a defesa da família e da vida, com ênfase na luta contra o aborto. Na entrevista, o deputado destacou que a campanha eleitoral teve como foco os eleitores católicos ${ }^{30}$.

Sobre a atuação desses dois deputados, destacaremos dois fatos que exem-

29.REIS, Marcos Vinicius de Freitas. Católicos carismáticos na política brasileira. Disponível em: http://iiiseminarioppgsufscar.files. wordpress.com/2012/04/ reis_marcos.pdf. Acesso em: 28 set. 2014.

30.CORRÁ, Daniel: SANTOS, Carlos. Novato na política, Flavinho priorizará na Câmara a luta contra o aborto. G1, 28 out. 2014. Disponível em: http://g1. globo.com/sp/vale-do-paraiba-regiao/eleicoes/2014/ noticia/2014/10/novato-na-politica-flavinho-priorizara-na-camara-luta-contra-o-aborto.html. Acesso em: 2 fev. 2018. plificam a forma como atuam no Congresso nacional e como articulam os elementos religiosos e políticos. Começaremos pelos posicionamentos por eles assumidos durante as discussões a respeito do Plano Nacional de Educação (PNE) na Câmara dos Deputados.

A partir da análise das postagens realizadas pelos dois deputados em suas páginas oficiais no Facebook, podemos perceber nítida postura combativa de ambos em relação a tudo o que por eles seria considerado "ideologia de gênero" e estaria presente no PNE enviado ao Congresso.

Embora o conceito careça de crítica mais aprofundada, por ora destacaremos apenas que sua utilização por Eros e Flavinho remete a uma visão pejorativa sobre tudo o que se refere a gênero e sexualidade. Para os deputados em questão, tratar de gênero no PNE seria questionar a heteronormatividade, ou seja, a norma cultural de que todos os indivíduos são heterossexuais, o que 
estabeleceria uma "confusão mental" nas crianças a partir do questionamento sobre a naturalidade do ser homem ou mulher.

A posição dos congressistas é em grande parte a publicização da opinião da Igreja Católica sobre o tema, sendo que, dos setores da Igreja, um dos que mais militam a respeito é a RCC. O movimento, por dar significativo valor às questões morais defendidas pelo catolicismo, foi caracterizado por Reginaldo Prandi (2008) como "renovação conservadora do catolicismo".

O segundo aspecto que consideramos relevante de ser destacado neste artigo no que tange à atuação desses congressistas é a promoção por um grupo carismático de oração semanal numa das salas de atividade parlamentar na Câmara dos Deputados. O encontro ocorre no formato tradicional de um grupo de oração da RCC, geralmente sob a liderança de Eros e Flavinho, que, além de conduzirem as orações e as pregações, também animam o encontro com seus violões.

Estas duas formas de atuação dos parlamentares, destacadas acima, demonstram quanto o mandato deles, para além da expressão dos interesses de uma parcela da população brasileira, é uma forma concreta de tornar público elementos simbólicos do movimento carismático. No momento em que criticam qualquer reflexão sobre a naturalização de gênero na Câmara dos Deputados, os parlamentares levam para o debate público um tema muito caro para a RCG e que constitui uma das principais bandeiras de militância social e religiosa do movimento.

\section{CONSIDERAÇÕES FINAIS}

Identificamos que a Renovação Carismática Católica, em seu início, articulou-se através dos "grupos de orações", porém rapidamente percebeu nos meios de comunicação de massa uma oportunidade privilegiada para conquistar fiéis, prestígio e poder. Valeu-se disso e articulou, de forma eficiente, seus instrumentos simbólicos com o carisma de suas lideranças religiosas, formando líderes carismáticos com significativa capacidade de mobilização das massas.

Valeu-se do processo de midiatização para permear o campo físico com representações dos produtos midiatizados, bem como o processo contrário, ou seja, a invasão das mídias no terreno do sagrado. Desse estreitamento entre a fé, mídia e vida privada, conseguiu transmitir o seu "ethos carismático" para outros espaços da Igreja e também da vida política e social.

Esse processo fez que também fosse possível adentrar no político. O poder eleitoral desse trabalho midiático possibilitou ao movimento eleger parlamentares fortemente articulados a suas causas. Os posicionamentos e opiniões de suas lideranças tornaram-se importantes para o balizamento de debates, que não são estritamente religiosos, mas que perpassam interesses da Igreja Católica. 
comunicação \& educação • Ano XXV • número 1 • jan/jun 2020

\section{REFERÊNCIAS BIBLIOGRÁFICAS}

BÍBLIA, N. T. Atos dos apóstolos. In: Bíblia de Jerusalém. São Paulo: Paulus, 2002.

CARRANZA, Brenda. Renovação Carismática Católica: origens, mudanças e tendências. Aparecida: Santuário, 2000.

CORRÁ, Daniel; SANTOS, Carlos. Novato na política, Flavinho priorizará na Câmara a luta contra o aborto. G1, 28 out. 2014. Disponível em: http://g1.globo.com/sp/vale-do-paraiba-regiao/eleicoes / 2014 / noticia/2014/10/novato-na-politica-flavinho-priorizara-na-camara-lutacontra-o-aborto.html. Acesso em: 2 fev. 2018.

FAUTO NETO, Antônio. Epistemologia do zigue-zague. In: FERREIRA, Jairo; FREITAS, Luiz Antonio Signates; PIMENTA, Francisco José Paoliello (org.). Estudos da comunicação: transversalidades epistemológicas. São Leopoldo: Editora Unisinos, 2010. p. 79-100.

FERNANDES, Sílvia Regina Alves. Padres cantores e a mídia: representações da identidade sacerdotal. Ciências Sociais e Religião, Porto Alegre, n. 7, p. 131-155, set. 2005.

FLORES, Ana Cassia. Práticas midiatizadas da Canção Nova na Internet, afetação de lógicas comunicacionais católicas e midiáticas. Dissertação (Mestrado em Comunicação Midiática) - Universidade Federal de Santa Maria, Santa Maria, 2010.

HERVIEU-LÉGER, Danièle. O peregrino e o convertido: A religião em movimento. Petrópolis: Vozes, 2008.

HJARVARD, Stig. The mediatization of society: A theory of the media as agents of social and cultural change. Nordicom Review, v. 29, n. 2, p. 105-134, 2008.

HJARVARD, Stig. Doing the right thing: Media and communication studies in a mediatized world. Nordicom Review, v. 33, n. 1, p. 27-34, 2012.

Hjarvard, Stig. Mediatization: conceptualizing cultural and social change. MATRIZes, São Paulo, v. 8, n. 1, p. 21-44, 2014.

KLEIN, Alberto. Imagens de culto e imagens de mídia: interferências midiáticas no cenário religioso. Porto Alegre: Sulina, 2006.

PRANDI, Reginaldo. Um sopro do espírito. São Paulo: Edusp, 1998.

PROCÓPIO, Carlos Eduardo Pinto. Carismatismo católico e eleições no Brasil. Ciências Sociais e Religião, v. 14, n. 16, p. 79-99, jun. 2012.

RASLAN FILHO, Gilson Soares. Dai-me almas: o pastoreio midiatizado da TV Canção Nova. Tese (Doutorado em Interfaces Sociais da Comunicação) Escola de Comunicações e Artes, Universidade de São Paulo, São Paulo, 2010. 
REIS, Marcos Vinicius de Freitas. Católicos carismáticos na política brasileira. Disponível em: http:/ /iiseminarioppgsufscar.files.wordpress.com/2012/04/ reis_marcos.pdf. Acesso em: 28 set. 2014.

RENOVAÇÃO CARISMÁTICA CATÓLICA BRASIL. Sereis batizados no Espírito Santo. Disponível em: https://rccbrasil.org.br/espiritualidadee-formacao/espirito-santo/595--sereis-batizados-no-espirito-santo.html. Acesso em: 4 mar. 2018.

SILVEIRA, Emerson José Sena da. Terços, "santinhos" e versículos: a relação entre católicos carismáticos e a política. Revista de Estudos da Religião REVER, ano 8, p. 54-74, mar. 2008.

SOUZA, André Ricardo de. As investidas católicas na mídia. Revista de Estudos da Religião - REVER, ano 8, p. 27-45, set. 2008.

VALLE, Edênio. A Renovação Carismática Católica: algumas observações. Estudos Avançados, v. 18, n. 52, p. 97-107, 2004. Disponível em: http:/ /www. scielo.br/pdf/ea/v18n52/a08v1852.pdf. Acesso em: 6 jun. 2019. 